\title{
PERFIL DA CLIENTELA DE UM PROGRAMA DE PRONTO-ATENDIMENTO PSICOLÓGICO A ESTUDANTES UNIVERSITÁRIOS ${ }^{1}$
}

\author{
Rodrigo Sanches Peres \\ Manoel Antonio dos Santos \\ Heidi Miriam Bertolucci Coelho"
}

\begin{abstract}
RESUMO. Pesquisas indicam que a caracterização da clientela de clínicas-escola de Psicologia fornece elementos para o aprimoramento dos serviços oferecidos. O presente estudo propõe-se a traçar o perfil sociodemográfico e clínico dos usuários do Programa de Pronto-Atendimento Psicológico ao Aluno da UNESP/Assis. Os dados indicam que a maioria dos usuários era ingressante na universidade, oriunda do curso de Psicologia, com idade entre 19 e 22 anos, do gênero feminino, não exercia atividade profissional remunerada, apresentava "dificuldades psicológicas moderadas" e foi encaminhada para psicoterapia. Tal caracterização subsidiou a implementação de mudanças nos serviços já existentes e a criação de novas modalidades de atendimento.
\end{abstract}

Palavras-chave: clínica-escola de psicologia, psicologia preventiva, psicoterapia.

\section{PROFILE OF CLIENTS ASSISTED BY A PSYCHOLOGICAL EMERGENCY SERVICE TO UNIVERSITY STUDENTS}

\begin{abstract}
Researches indicate that the characterization of the clientele of university psychology clinics provides information to the service improvement. This study aims to draw the social-demographic and clinic profile of the clients assisted by the Service of Student Psychological Emergency of UNESP/Assis during 2000 and 2001. Data indicate that most of the clients were female students of Psychology, recently enrolled at the university, aging from 19 to 22 . They initially complained about moderate psychological distress and initiated psychotherapy. The analysis of this characterization has supported changes in the service and the creation of new service modalities.
\end{abstract}

Key words: University Psychology Clinic, preventive psychology, psychotherapy.

\section{INTRODUÇÃO}

As Clínicas-Escola de Psicologia têm como finalidade básica possibilitar o treinamento de alunos mediante a aplicação dos conhecimentos teóricos adquiridos em sala de aula, o que pode contribuir para a formação de profissionais adequadamente habilitados e capazes de expandir as práticas psicológicas em consonância com as novas realidades e demandas sociais, políticas e culturais da atualidade. Além disso, as Clínicas-Escola também exercem um papel social de extrema importância, uma vez que oferecem à população economicamente desfavorecida uma possibilidade de acesso a serviços psicológicos gratuitos ou de baixo custo financeiro (Herzberg, 1996).

Tendo em vista sua indiscutível relevância, as Clínicas-Escola têm sido objeto de diversos estudos recentes, que focalizam, em linhas gerais, desde a caracterização da clientela (Santos, Moura, Pasian \& Ribeiro, 1993; Enéas, Faleiros \& Sá, 2000; Peres \& Coelho, 2001) e a descrição dos serviços oferecidos (Santos, 1987; Yamamoto, 1997; Silvares, 2000; Mito, 2001) até a problematização das dificuldades inerentes

1 Uma versão preliminar deste estudo foi apresentada no X Congresso de Iniciação Científica da Universidade Federal de São Carlos.

* Psicólogo, acadêmico do Curso de Pós- Graduação em Psicologia da Faculdade de Filosofia, Ciências e Letras de Ribeirão Preto (USP), bolsista FAPESP.

\# Psicólogo, Mestre e Doutor em Psicologia pela USP, docente Faculdade de Filosofia, Ciências e Letras de Ribeirão Preto (USP).

II Psicóloga, Mestre em Psicologia pela Faculdade de ciências e letras de Assis (UNESP), membro associado do Núcleo de psicanálise de Marília e região. 
ao trabalho clínico-institucional (Ropa \& Duarte, 1985; Silvestre, 1987; Tozoni-Reis, 1994; Silvares, 1996) e a elaboração de novas propostas de intervenção, que se diferenciam das modalidades de atendimento tradicionalmente oferecidas (Simon, 1989; Peres, 1997; Vaisberg \& Machado, 1999; Peres, 2001; Barros, Corrêa \& Germano Jr., 2001; Salinas \& Santos, 2002). Tais estudos têm se mostrado imprescindíveis tanto para o aprimoramento das práticas clínicas já existentes - a partir da avaliação dos níveis de resolutividade das estratégias oferecidas e da identificação das reais necessidades da população - quanto para a criação de novos serviços ou modalidades de atendimento.

$\mathrm{O}$ presente estudo se insere nessa temática e focaliza a apresentação de dados sociodemográficos e clínicos da clientela de um programa de prontoatendimento psicológico desenvolvido no âmbito da Clínica-Escola de uma universidade pública do Estado de São Paulo e voltado especificamente à comunidade discente interna.

\section{CARACTERÍSTICAS GERAIS DO SERVIÇO}

Vinculado à Faculdade de Ciências e Letras de Assis da Universidade Estadual Paulista (UNESP), o Programa de Pronto-Atendimento Psicológico ao Aluno (PPAPA) foi criado em 1998, com o intuito de oferecer à comunidade discente da unidade uma possibilidade de acolhimento psicológico mediante a abertura de um lugar de escuta clínica. O referido serviço foi implementado em virtude da necessidade de, num primeiro momento, organizar e otimizar os recursos da instituição para que fosse possível, num segundo momento, prestar atendiento aos alunos que, em número crescente, solicitavam apoio psicológico junto ao Centro de Pesquisa e Psicologia Aplicada (CPPA) da unidade. Assim sendo, o PPAPA foi criado para preencher uma lacuna e atender a uma procura já existente e cada vez maior.

O PPAPA funciona, antes de tudo, como um espaço de escuta e acolhimento, que visa essencialmente a oferecer ao usuário uma possibilidade de "ventilação" de sentimentos e angústias. No entanto, o PPAPA pode também, de acordo com as características de cada caso, desempenhar o papel que compete a um serviço de triagem e encaminhamento, ou seja, avaliar com maior precisão as condições dos usuários, com o intuito de obter os elementos necessários para a identificação da modalidade de intervenção mais adequada a ser sugerida. Os procedimentos adotados, conse- üentemente, são variáveis: pode-se limitar a intervenção a apenas uma sessão de prontoatendimento, realizar duas ou três sessões e encaminhar o aluno para psicoterapia individual ou grupal, para outros serviços vinculados ao Programa e/ou introduzir novas estratégias de atendimento, se necessário.

Dessa forma, nos parece possível afirmar que, em linhas gerais, o PPAPA guarda algumas semelhanças tanto com o tratamento de ensaio de Freud (1911/1994) quanto com a proposta das entrevistas preliminares de Lacan (Wachsberger, 1989; Priszkulnik, 1998), pois visa não apenas a oferecer um acolhimento inicial ao usuário, mas também a coligir dados para a definição do direcionamento da intervenção. Cumpre assinalar, contudo, que, independentemente do encaminhamento do caso, esse acolhimento inicial se afigura, por si só, como uma intervenção, uma vez que representa um espaço privilegiado que pode levar o usuário a refletir sobre suas queixas (Salinas \& Santos, 2002).

\section{CARACTERÍSTICAS GERAIS DO CONTEXTO NO QUAL O SERVIÇO ESTÁ INSERIDO}

Assis é um município de aproximadamente 90 mil habitantes, situado no Oeste do Estado e distante cerca de 450 quilômetros de São Paulo. Possui um perfil econômico diversificado, com base na agricultura e comércio. Além disso, a cidade atualmente tem desenvolvido seu potencial industrial, de modo que se tornou, nos últimos anos, um dos principais municípios do Médio Paranapanema. A Faculdade de Ciências e Letras de Assis foi criada em 16 de Agosto de 1958 e contava, quando da realização do presente estudo, com quatro cursos de graduação - Psicologia, Letras, História e Biologia - e uma área de $125.000 \mathrm{~m} 2$. No ano de 2001 encontravam-se regularmente matriculados em tais cursos 1439 alunos, sendo a maior parte deles proveniente de outras cidades do Estado de São Paulo e até mesmo de outras regiões do país.

\section{CARACTERÍSTICAS GERAIS DAS DIFERENTES ESTRATÉGIAS DE INTERVENÇÃO}

Os atendimentos do PPAPA são gratuitos e conduzidos por seis estagiários - previamente aprovados em um processo seletivo realizado anualmente - de duas turmas do $4^{\circ}$ e $5^{\circ}$ anos do curso de graduação em Psicologia da unidade. As sessões duram cerca de cinqüenta minutos e os estagiários se 
revezam, de segunda a sexta-feira, em dois plantões diários de três horas. Pode-se agendar previamente o atendimento junto à Recepção do CPPA ou solicitá-lo de imediato, caso haja um estagiário disponível no momento. Com o intuito de promover a avaliação dos atendimentos e, consequientemente, subsidiar o delineamento do(s) encaminhamento(s) mais apropriado(s) para cada caso, uma psicóloga de orientação psicanalítica vinculada ao CPPA conduz, individualmente e em grupo, supervisões teóricas e clínicas semanais.

Muitos usuários procuram o serviço com queixas aparentemente circunstanciais e demonstram interesse apenas em "desabafar", como eles mesmos relatam. $\mathrm{Na}$ maioria das vezes, tais queixas sugerem, a princípio, a existência de uma demanda de escuta e acolhimento pontual. Os estagiários responsáveis pelo atendimento de casos desse tipo, não obstante, não partem de uma escuta a priori - ou seja, não norteiam a escuta em função do pressuposto de que a demanda é circunscrita somente a essa queixa inicial - e procuram investigar a suposição sobre a qual se funda a demanda do sujeito, com o intuito de verificar se há algo para além da queixa (Silvestre, 1987).

Não obstante, a experiência do serviço sugere que a maioria dos alunos que apresentam queixas dessa categoria não direciona seus questionamentos para si próprios e não se inclui em seus "sintomas". Muitos deles, na realidade, explicitam que procuraram o serviço apenas para aliviar-se momentaneamente das angústias decorrentes de dificuldades circunstanciais e que não possuem interesse em dar início a um processo psicoterapêutico. Nesses casos, usualmente o serviço faz as vezes de um espaço de escuta e acolhimento do ponto emergencial que motiva a procura. Assim, a intervenção limita-se a apenas uma ou duas sessões de pronto-atendimento. De qualquer forma, o estagiário responsável coloca-se à disposição para uma outra sessão, que pode ser agendada para a semana subseqüente ou solicitada posteriormente, caso o usuário o julgue necessário.

Por outro lado, o PPAPA também recebe alunos que apresentam queixas d denotadoras da existência de uma demanda de tratamento. $\mathrm{O}$ procedimento mais adotado nessas ocasiões é realizar uma primeira sessão e sugerir ao usuário um segundo atendimento na semana subseqüiente (ou até mesmo ao final da semana do primeiro atendimento, se necessário). Dessa forma, tem-se tempo hábil para que, a partir da discussão do caso em supervisão, seja possível elaborar hipóteses diagnósticas ponderadas e definir, conseqüentemente, $\mathrm{o}(\mathrm{s})$ encaminhamento(s) mais adequado(s) a $\operatorname{ser}(\mathrm{em})$ sugerido(s).
No segundo atendimento, então, o estagiário responsável sugere $\mathrm{o}(\mathrm{s})$ encaminhamento(s) considerado(s) mais apropriado(s) e verifica o interesse e a disponibilidade do usuário em aderir à(s) proposta(s), que pode(m) compreender desde psicoterapia individual ou grupal (conduzida na Unesp/Assis por estagiários do PPAPA ou de outros núcleos, por profissionais da rede pública de saúde do município e região ou profissionais conveniados que atuam em consultórios particulares) até oficinas de convivência (realizadas esporadicamente com o intuito de promover a integração dos alunos da unidade) e/ou grupos de convivência temáticos (grupos abertos e regulares, que visam à integração dos alunos da unidade e adotam recursos diversificados, tais como teatro, música, prática de esportes e discussão de assuntos relacionados à sexualidade). Nesses casos, o PPAPA funciona não apenas como um lugar de escuta e acolhimento, mas também como um serviço de triagem e encaminhamento.

\section{OBJETIVO}

O presente estudo tem como objetivo delinear o perfil da clientela do Programa de Pronto-Atendimento Psicológico ao Aluno (PPAPA) da Unesp/Assis, focalizando mais especificamente alguns dados sociodemográficos (gênero, idade, curso universitário, seriação, atividade profissional) e clínicos (as queixas iniciais e os encaminhamentos) dos usuários que recorreram ao serviço no biênio 2000-2001.

\section{METODOLOGIA}

Tendo em vista o objetivo proposto, o presente estudo adotou o referencial metodológico da pesquisa documental, priorizando um caráter descritivo, retrospectivo e com abordagem quantiqualitativa. Assim sendo, esta investigação se alinha no enfoque da pesquisa naturalística, uma vez que as investigações científicas desse tipo não têm como propósito principal testar hipóteses, mas sim descrever um fenômeno (as características de alunos universitários que procuram um serviço psicológico, no caso) tal como ele naturalmente ocorre e nas circunstâncias que espontaneamente o geram (Selltiz, Wrightsman \& Cook, 1987).

\section{Procedimento para a coleta de dados}

A coleta de dados foi realizada a partir de consultas aos prontuários do PPAPA referentes aos 
casos novos atendidos no biênio 2000-2001. Constavam de tais prontuários informações coletadas pelo estagiário responsável pelo atendimento - referentes à identificação pessoal do usuário (nome, endereço, telefone, gênero, idade, cidade de origem, curso, seriação e atividade profissional) e uma breve descrição da queixa inicial e do encaminhamento indicado.

\section{RESULTADOS: APRESENTAÇÃO E DISCUSSÃO}

Os prontuários do PPAPA indicam que 58 alunos foram atendidos em 2000. No ano seguinte houve um aumento da demanda, de modo que o serviço registrou 79 usuários. Tomando-se como base o número de alunos regularmente matriculados nos cursos de graduação da unidade no mesmo período (1425 em 2000 e 1439 em 2001), pode-se inferir que a quantidade de atendimentos realizados foi modesta. No entanto, levando-se em conta o número de usuários beneficiados pelo PPAPA nos anos anteriores, vê-se que houve um aumento da quantidade de atendimentos desde a criação do Programa, como ilustra a Figura 1. Ademais, deve-se levar em conta que o serviço é relativamente recente, de modo que ainda não foi devidamente incorporado à "cultura" do campus. Pensando nisso, a divulgação do PPAPA tem sido enfatizada recentemente, por meio de cartazes espalhados pela unidade e visitas dos estagiários às salas de aula.

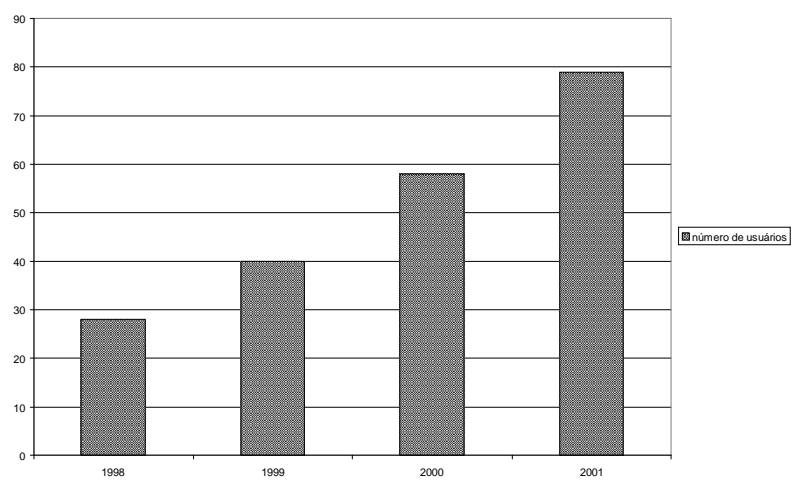

Figura 1. Distribuição dos usuários do serviço em função do ano.

A maior parte dos usuários do PPAPA no biênio 2000-2001 foi do gênero feminino $(n=48$, aproximadamente $83 \%$ em 2000 e $n=66$, aproximadamente $84 \%$ em 2001), como aponta a Figura 2. O fato de haver uma notável predominância de mulheres na composição da clientela do serviço, no entanto, já era previsto, uma vez que a maioria dos estudantes dos cursos de Letras, Psicologia e Biologia da unidade é do sexo feminino. Além disso, outros estudos voltados à caracterização dos usuários de Clínicas-Escola destacam que geralmente há uma procura maior de atendimento psicológico por parte das mulheres (Santos e cols., 1993; Enéas e cols., 2000).

Pode-se pensar que tais achados refletem os condicionamentos socioculturais moldados pelas relações de gênero, uma vez que durante o processo de socialização primária e secundária há uma construção de gênero que modela as características psicológicas mais associadas a cada sexo e determina, por exemplo, que as mulheres devem externalizar suas emoções e solicitar ajuda sempre que necessário, ao passo que os homens, ao contrário, devem desde cedo ocultar seus sentimentos e aflições psíquicas e cultivar a coragem heróica, a bravura e a resistência à manifestação emocional diante das adversidades que enfrentam no cotidiano.

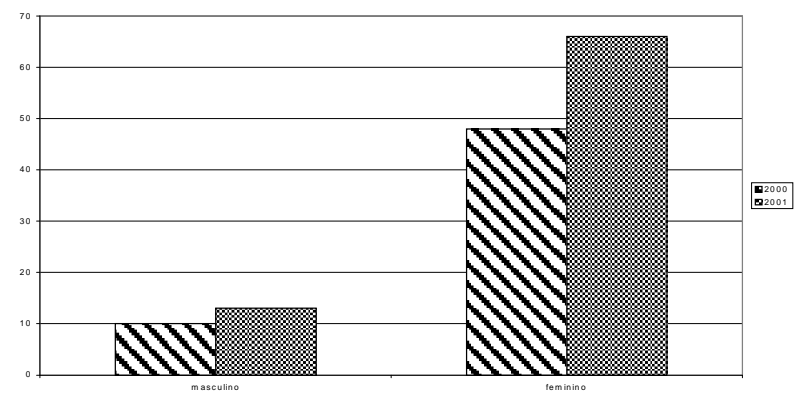

Figura 2. Distribuição dos usuários em função do gênero.

No que concerne à faixa etária dos usuários, os registros do PPAPA indicam que a maioria dos alunos que recorreram ao atendimento psicológico oferecido pelo serviço tinha de 19 a 22 anos $(n=35$, aproximadamente $60 \%$ em 2000 e $n=55$, aproximadamente $69 \%$ em 2001), como demonstra a Figura 3. Tais dados sugerem que a clientela do PPAPA tende a ser primordialmente constituída por jovens que se aproximam da maioridade ou que a tenham obtido há pouco. Pode-se pensar que esse fenômeno deve-se, em parte, ao fato de ser o período de transição entre o final da adolescência e o início da vida adulta uma fase usualmente marcada por incertezas e crises existenciais que podem culminar com a eclosão e/ou acentuação de conflitos psicológicos (Yamamoto, 1997). Em contrapartida, faz-se necessário destacar também que tal dado, de certa forma, era esperado, uma vez que a maior parte dos universitários do país ingressa no ensino superior com cerca de 20 anos de idade. 


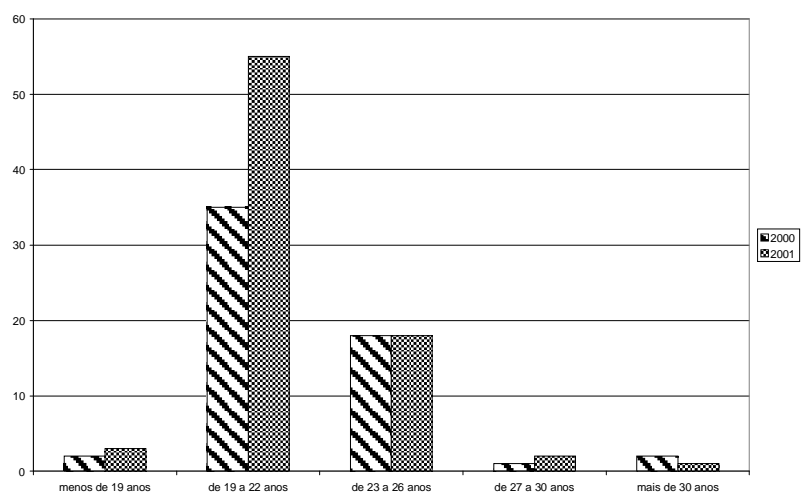

Figura 3. Distribuição dos usuários em função da faixa etária.

A Figura 4 evidencia que a maioria dos alunos atendidos era ingressante na universidade $(n=29$, isto é, $50 \%$ em 2000 e $n=40$, aproximadamente $53 \%$ em 2001). Pode-se supor que a predominância de "calouros" entre os usuários do serviço esteja intimamente associada ao fato de haver na Unesp/Assis um grande número de alunos procedentes de outras cidades e Estados, uma vez que, como discutiremos de forma mais pormenorizada adiante, uma parcela considerável da clientela procura o PPAPA em virtude de dificuldades de se distanciar pela primeira vez, na maioria das situações - do contexto familiar e de outras pessoas queridas do município de origem e estabelecer novos vínculos afetivos em uma cidade desconhecida. Além disso, a ocorrência de tal fenômeno pode ser considerada uma tendência em serviços de atendimento psicológico voltados especificamente a estudantes universitários, uma vez que também foi apontada por outros estudos (Calejón, 1996; Yamamoto, 1997).

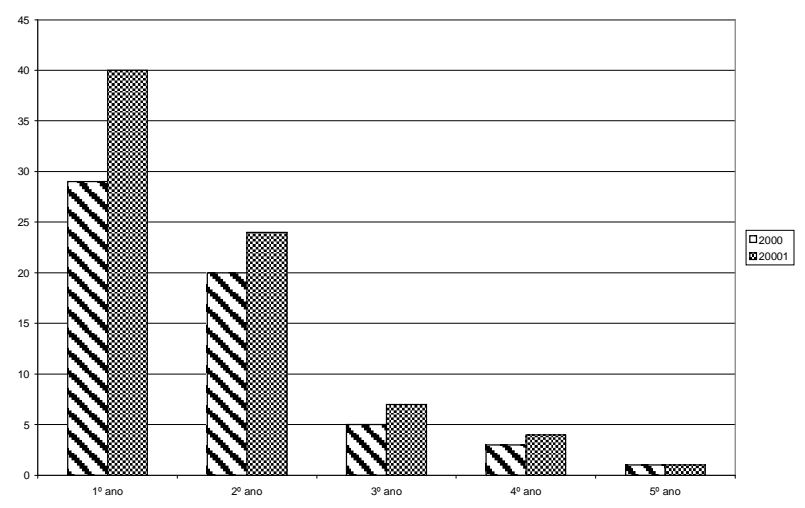

Figura 4. Distribuição dos usuários em função da seriação.

A maioria expressiva dos alunos atendidos pelo serviço no biênio 2000-2001 ( $n=50$, aproximadamente $86 \%$ em 2000 e $n=71$, aproximadamente $90 \%$ em 2001) não exercia nenhuma atividade profissional remunerada. Pode-se supor que tais alunos dependiam do auxílio financeiro dos pais e/ou familiares para dar continuidade ao curso e presumivelmente encontrariam dificuldades financeiras em arcar com o ônus de um atendimento psicológico particular. Evidencia-se, assim, a importância de oferecer a essa população um serviço gratuito, por intermédio das atividades do PPAPA, ou a preços reduzidos, por meio de convênios firmados com profissionais que atuam em consultórios particulares e se comprometem a prestar, mediante a cobrança de valores acessíveis, atendimento psicológico aos alunos encaminhados pela instituição.

Os registros do PPAPA apontam que a clientela do serviço tende a ser constituída primordialmente por discentes do curso de Psicologia $(n=27$, aproximadamente $47 \%$ em 2000 e $n=33$, aproximadamente $41 \%$ em 2001), como se observa na Figura 5. Tal fenômeno pode ser analisado de diversas formas. Inicialmente, poder-se-ia supor que muitos dos alunos de Psicologia que procuraram o serviço o fizeram com o intuito de conhecer na prática um dos campos de atuação da carreira que optaram por abraçar. Além disso, poder-se-ia especular que uma parcela considerável desses alunos recorreu ao serviço em função das recomendações dos docentes do curso de Psicologia, que usualmente indicam o processo psicoterapêutico como um importante recurso auxiliar para a formação profissional da área, sobretudo para os interessados em atuar futuramente no âmbito clínico.

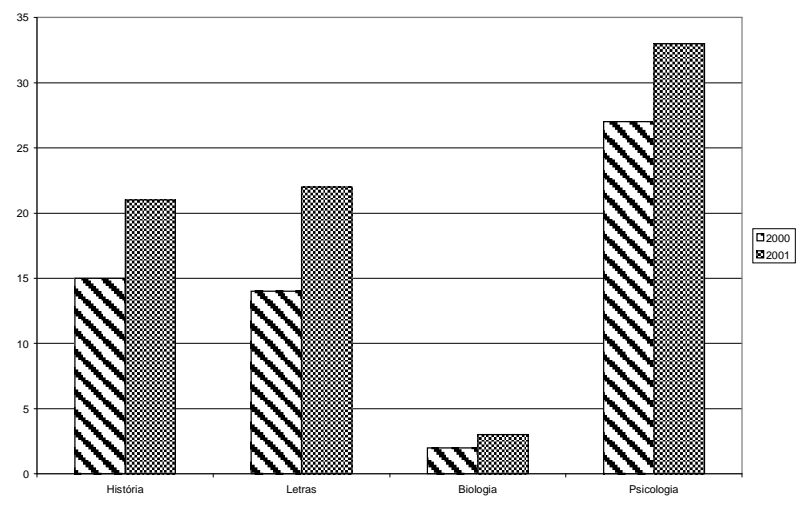

Figura 5. Distribuição dos usuários em função do curso.

A experiência do PPAPA, não obstante, tem evidenciado que tais hipóteses não correspondem à realidade, uma vez que nenhum dos usuários do serviço no biênio 2000-2001 mencionou os referidos fatores como motivadores da decisão de buscar atendimento psicológico. $\mathrm{Na}$ prática, tem-se notado que os alunos de Psicologia, possivelmente por possuírem uma visão mais realística - ou menos preconceituosa - acerca dos objetivos de um processo 
psicoterapêutico, tendem a procurar o PPAPA com menos resistências e mais naturalidade do que os discentes de outros cursos, o que, de certa forma, justifica o achado em questão. Ademais, pode-se supor que tem havido uma divulgação "informal" mais eficiente do serviço entre os discentes de Psicologia, uma vez que os estagiários responsáveis pela condução do PPAPA geralmente mantêm - devido à própria disposição das salas de aula da unidade - uma proximidade maior com os companheiros de curso do que com os demais alunos.

O fato de haver uma quantidade considerável de alunos de Psicologia entre os usuários do PPAPA obviamente exige dos estagiários responsáveis pelos atendimentos uma atenção redobrada às questões éticas e técnicas. Não temos como objetivo, no presente estudo, apresentar reflexões pormenorizadas a esse respeito, mas consideramos relevante destacar que o manejo de tais questões é norteado basicamente em função de três "cuidados especiais". Em primeiro lugar, evita-se, por razões óbvias, que os usuários do serviço sejam atendidos por estagiários com os quais já tenham tido algum contato social anterior. Em segundo lugar, a questão do sigilo e a definição do setting são enfatizadas. Em terceiro lugar, a transferência e a contratransferência são analisadas com desvelo durante as supervisões, com o intuito de evitar que os processos recíprocos de identificação (do aluno com o estagiário e vice-versa) prejudiquem o atendimento.

Em última análise, tais precauções - assim como outros cuidados menos representativos, mas igualmente importantes - têm-se mostrado indispensáveis para o adequado funcionamento do serviço e evidenciado que a adequação da técnica à ética - e não o contrário - é capaz de subsidiar a reorganização das modalidades de atendimento psicológico no âmbito das instituições, promovendo a criação de novas práticas clínicas em conformidade com novas demandas emergentes (Salinas \& Santos, 2002).

As queixas iniciais apresentadas pelos usuários foram agrupadas em três categorias básicas, a saber: 1) dificuldades psicológicas circunstanciais (tais como ansiedade frente às provas do curso universitário e desentendimentos ocasionais com companheiros de moradia); 2) dificuldades psicológicas moderadas (como, por exemplo, dificuldades de se distanciar da família e das pessoas queridas do município de origem e estabelecer vínculos na nova cidade) e 3) dificuldades psicológicas severas (tais como alcoolismo, drogadição, depressão e tentativa de suicídio). Cumpre assinalar que tais categorias são intencionalmente abrangentes, uma vez que, segundo os dados dos prontuários, os alunos atendidos pelo PPAPA no biênio 2000-2001 apresentaram queixas iniciais bastante diversificadas. Ademais, na maioria dos casos, as informações constantes dos prontuários, no que diz respeito às queixas iniciais, não seguiam um padrão comum e mostraram-se pouco detalhadas, o que dificultou a elaboração de categorias mais específicas dos motivos de consulta.

As queixas iniciais apresentadas com maior frequiência pelos usuários do serviço são relacionadas à categoria $2(n=26$, aproximadamente $45 \% \mathrm{em} 2000 \mathrm{e}$ $n=33$, aproximadamente $41 \%$ em 2001), como aponta a Figura 6. Faz-se necessário esclarecer, porém, que foram incluídas nesta categoria dificuldades aparentemente circunstanciais, tais como dificuldades de se distanciar da família e das pessoas queridas da cidade de origem e estabelecer novos vínculos em Assis, uma vez que a experiência do PPAPA tem evidenciado que, na maioria das vezes, queixas desse tipo freqüentemente mascaram um conflito psicológico subjacente mais significativo.

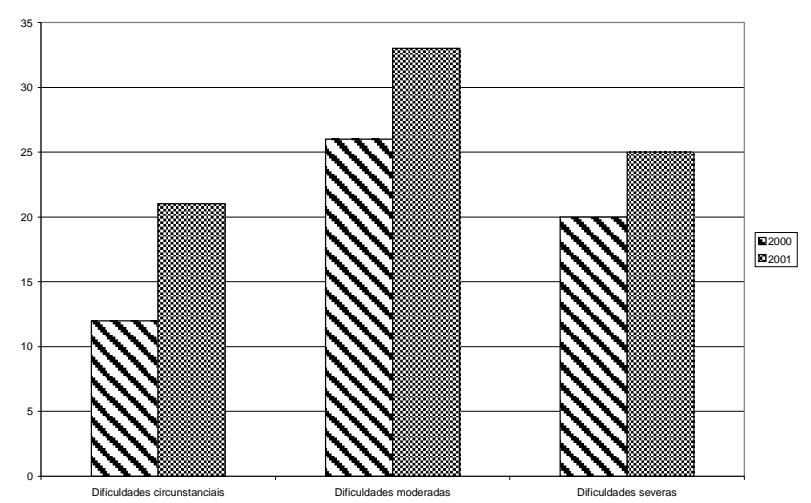

Figura 6. Distribuição dos usuários em função da queixa inicial.

A maior parte da clientela do PPAPA foi encaminhada para psicoterapia individual, conduzida posteriormente por estagiários do CPPA $(n=18$, aproximadamente $31 \%$ em 2000 e $n=25$, aproximadamente $31 \%$ em 2001) ou por profissionais conveniados ( $n=14$, aproximadamente $24 \%$ em $2000 \mathrm{e}$ $n=22$, aproximadamente $28 \%$ em 2001), como mostra a Figura 7. Dessa forma, nota-se que há, aparentemente, uma incongruência entre as queixas iniciais apresentadas pela maioria dos usuários (dificuldades psicológicas moderadas) e a modalidade de encaminhamento mais freqüente (psicoterapia individual). No entanto, deve-se levar em conta que, como exposto anteriormente, na maioria dos casos em que um aluno procura o PPAPA em virtude de 
dificuldades psicológicas moderadas, nota-se, nas entrelinhas da queixa inicialmente apresentada, a existência subjacente de um conflito psicológico mais severo, o que justificava o encaminhamento para psicoterapia individual.

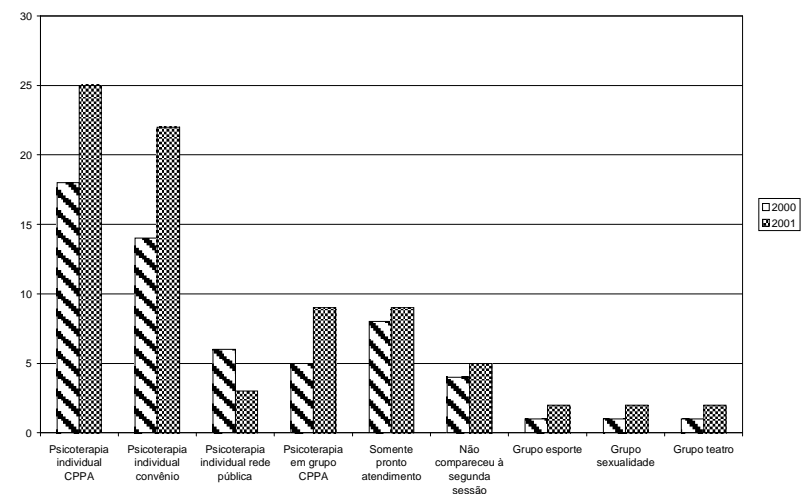

Figura 7. Distribuição dos usuários em função da modalidade de encaminhamento.

Tendo-se em vista o delineamento das modalidades de encaminhamento mais e menos empregadas, evidenciou-se a necessidade de ampliar as vagas para psicoterapia individual no PPAPA, nos convênios estabelecidos com profissionais que atuam em consultórios particulares e - sobretudo - na rede pública de saúde do município. Além disso, nos pareceu importante reestruturar os grupos temáticos e as oficinas de convivência, que foram pouco acionados. Por fim, consideramos relevante destacar que poucos alunos ( $n=4$, aproximadamente $7 \% \mathrm{em}$ 2000 e $n=5$, aproximadamente $6 \%$ em 2001) interromperam a intervenção antes do desfecho planejado e não retornaram para o segundo atendimento, o que pode ser considerado um indicador positivo da aceitação do serviço por parte da população assistida.

\section{CONSIDERAÇÕES FINAIS}

Os dados sistematizados a partir das informações coletadas junto aos prontuários do PPAPA indicam que a maioria dos usuários do serviço no biênio 20002001 era ingressante na universidade, tinha de 19 a 22 anos, era do gênero feminino e oriunda do curso de Psicologia, não exercia atividade profissional remunerada, apresentou queixas iniciais relacionadas a dificuldades psicológicas moderadas e foi encaminhada para psicoterapia. A análise de tais dados permitiu a elaboração de um perfil inicial da clientela e subsidiou a implementação de mudanças na organização do serviço. Nesse sentido, tem-se procurado ampliar o número de vagas para psicoterapia junto ao CPPA, reestruturar os grupos temáticos e as oficinas de convivência e criar atividades voltadas à promoção da integração dos alunos à cidade e à universidade. Dessa forma, o PPAPA permanece constantemente aberto a reformulações e reestruturações, com o objetivo de aprimorar os serviços prestados, cuja relevância vem sendo corroborada pela experiência acumulada desde o início de sua implantação.

Cumpre assinalar, por fim, que o presente estudo evidenciou também a necessidade de modificar a forma de coleta e registro de dados, tanto clínicos quanto sociodemográficos, dos usuários do serviço. Assim, elaborou-se uma nova ficha de cadastro, contendo campos para o preenchimento de informações consideradas pertinentes e que antes não eram registradas, tais como estado civil, composição familiar, posição na fratria, renda familiar mensal e tipo de moradia na cidade ("república", pensão, alojamento, etc.). Ademais, os estagiários responsáveis pelos atendimentos têm sido treinados para preencher adequadamente a ficha de cadastro e padronizar as informações referentes às queixas iniciais e ao encaminhamento. Dessa forma, será possível apresentar uma caracterização mais pormenorizada da clientela do serviço em estudos posteriores.

\section{REFERÊNCIAS}

Barros, L., Corrêa, L.C.C. \& Germano Jr., A. (2001) Psicodiagnóstico interventivo em instituição. Em Universidade Presbiteriana Mackenzie (Org.), Anais do I Congresso de Psicologia Clínica (79-82). São Paulo.

Calejón, L.M.C. (1996) Manejo de crises e dificuldades adaptativas de universitários. Tese de Doutorado NãoPublicada, Programa de Pós-Graduação em Psicologia Escolar e do Desenvolvimento Humano, Instituto de Psicologia, Universidade de São Paulo, São Paulo.

Enéas, M.L.E., Faleiros, J.C. \& Sá, A.C.A. (2000) Uso de psicoterapias breves em clínica-escola: caracterização dos processos com adultos. Psicologia: Teoria e Prática 2 (2), 9-30.

Freud, S. (1994) Sobre o início do tratamento (J.O.A. Abreu, Trad.). Em J. Salomão (Org.), Edição Standard Brasileira das Obras Completas de Sigmund Freud (Vol. XII, pp.135158). Rio de Janeiro, RJ: Imago (Original publicado em 1911).

Herzberg, E. (1996) Reflexões sobre o processo de triagem de clientes a serem atendidos em clínicas-psicológicasescola. Em R.M.L.L. Carvalho (Org.) Repensando a formação do psicólogo: da informação à descoberta (pp. 147-154). Campinas, SP: Alínea (Coletâneas da ANPEPP, v. 1, n. 9). 
Mito, T.I.H. (2001) Psicoterapia breve infantil: eixos norteadores do processo. Em Universidade Presbiteriana Mackenzie (Org.), Anais do I Congresso de Psicologia Clínica_(157-163). São Paulo, SP.

Peres, R. S. (2001) Pronto-atendimento psicológico: uma possibilidade de intervenção da clínica contemporânea [Resumo]. Em: Sociedade Interamericana de Psicologia (Org.), Anais do XXVIII Congresso Interamericano de Psicologia (CD-ROM). Santiago, Chile.

Peres, R. S. \& Coelho, H.M.B. (2001) Caracterização dos usuários do pronto-atendimento psicológico da clínicaescola da UNESP/Assis em 2000 [Resumo]. Em Universidade Federal de São Carlos (Org.), Anais do IX Congresso de Iniciação Científica da UFSCar_(CD-ROM). São Carlos, SP.

Peres, V.L.A. (1997) Triagem psicológica grupal: procedimento e resultados obtidos com lista de espera de crianças, adolescentes e adultos em uma clínica-escola de psicologia. Paidéia 12/13, 63-76.

Priszkulnik, L. (1998) As entrevistas diagnósticas em psicanálise. Psychê 2 (2), 17-23.

Ropa, D. \& Duarte, L.F. (1985) Considerações teóricas sobre a questão do "atendimento psicológico" às classes trabalhadoras. Em S.A. Figueira (Org.) Cultura da psicanálise (178-201). São Paulo: Brasiliense.

Salinas, P. \& Santos, M.A. (2002) Serviço de triagem em clínica-escola de psicologia: a escuta analítica em contexto institucional. Psychê 6 (9), 177-196.

Santos, M.A. (1987) O psicodiagnóstico infantil em grupo: uma experiência em instituição. Arquivos Brasileiros de Psicologia 39 (2), 3-17.

Santos, M.A., Moura, L., Pasian, S.R. \& Ribeiro, P.L.L. (1993) Caracterização da clientela de adolescentes e adultos de uma clínica-escola de Psicologia. Psicologia: Teoria e Pesquisa 9 (1), 123-144.
Selltiz, C., Wrightsman, L.S. \& Cook, S.W. (1987) Dados de observação e de arquivo (M.M.H. d'Oliveira \& M.M. del Rey, Trads.). Em L.H. Kidder (Org.) Métodos de pesquisa nas relações sociais. (Vol. 2: Medidas na pesquisa social, pp. 95-120). São Paulo, SP: EPU

Silvares, E.F.M. (1996) É satisfatório o atendimento psicológico nas clínicas-escola brasileiras? Em: R.M.L.L. Carvalho (Org.) Repensando a formação do psicólogo: da informação à descoberta (pp. 137-147). Campinas, SP: Alínea (Coletâneas da ANPEPP, v. 1, n. 9).

Silvares, E.F.M. (2000) Invertendo o caminho tradicional do atendimento psicológico em uma clínica-escola brasileira. Estudos de Psicologia 5 (1), 149-180.

Silvestre, D. (1987) Problemas y particularidades de la demanda de analisis en institucion. Em E. Laurent (Org.) El significante de la transferencia (89-94). Buenos Aires: Manantial.

Tozoni-Reis, J.R. (1994) Psicoterapia na rede pública de saúde. Temas em Psicologia 2, 177-188.

Simon, R. (1989) Psicologia clínica preventiva: novos fundamentos. São Paulo, SP: EPU.

Vaisberg, T.M.J.A. \& Machado, M.C.L (1999) Diagnóstico estrutural de personalidade em psicopatologia psicanalítica. Psicologia USP 11 (1), 29-48.

Wachsberger, H. (1989) Função das entrevistas preliminares (L. Forbes, Trad.). Em M.B. Motta (Org.) Clínica lacaniana (pp. 26-31). Rio de Janeiro, RJ: Jorge Zahar.

Yamamoto, K. (1997) Prevenção de distúrbios adaptativos em estudantes universitários. Mudanças 8, 267-273.

Recebido em 14/07/2003 Aceito em 25/02/2004

Endereço para correspondência: Rodrigo Sanches Peres, Rua Jesuíno de Arruda, 2753, Centro 13560-060, São Carlos-SP. E-mail: rodrigo_sanches_peres@hotmail.com 